AperTO - Archivio Istituzionale Open Access dell'Università di Torino

Individual data meta-analysis for the study of survival after pulmonary metastasectomy in colorectal cancer patients: A history of resected liver metastases worsens the prognosis

This is the author's manuscript

Original Citation:

Availability:

This version is available http://hdl.handle.net/2318/1690853

since 2019-02-06T18:45:53Z

Terms of use:

Open Access

Anyone can freely access the full text of works made available as "Open Access". Works made available under a Creative Commons license can be used according to the terms and conditions of said license. Use of all other works requires consent of the right holder (author or publisher) if not exempted from copyright protection by the applicable law. 


\section{Individual data meta-analysis for the study of survival after pulmonary metastasectomy in colorectal cancer patients: A history of resected liver metastases worsens the prognosis}

Jon Zabaleta ${ }^{\mathrm{a}, *}$, Tomohiko Iida ${ }^{\mathrm{b}}$, Pierre E. Falcoz ${ }^{\mathrm{c}}$, Samer Salah ${ }^{\mathrm{d}}$, José R. Jarabo ${ }^{\mathrm{e}}$, Arlene M.

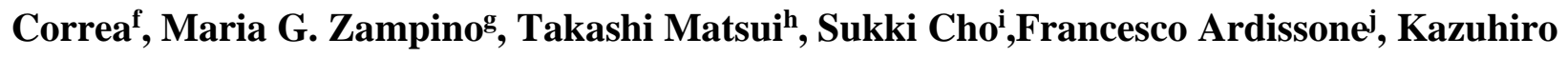
Watanabe $^{\mathrm{k}}$, Michel Gonzalez, Pascal Gervaz ${ }^{\mathrm{m}}$, Jose I. Emparanzan ${ }^{\mathrm{n}}$, Víctor Abrairao

${ }^{a}$ Thoracic Surgery Service, Hospital Universitario Donostia, Paseo Dr Beguiristain s/n, Donostia, 20014, Gipuzkoa, Spain

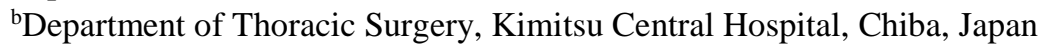

'Department of Thoracic Surgery, Strasbourg University Hospital, Strasbourg, France

${ }^{\mathrm{d}}$ Medical Oncology Department, King Hussein Cancer Center, Amman, Jordan

eDepartment of Thoracic Surgery, Hospital Clínico San Carlos, Madrid, Spain

${ }^{\mathrm{f}}$ Department of Thoracic and Cardiovascular Surgery, University of Texas MD Anderson Cancer Center, Houston, USA sUnit of Gastrointestinal Medical Oncology and Neuroendocrine Tumors, European Institute of Oncology, Milan, Italy

hDepartment of Colorectal Surgery, Tochigi Cancer Center, Tochigi, Japan

iDepartment of Thoracic and Cardiovascular Surgery, Seoul National University Bundang Hospital, Seoul, South Korea ${ }^{j}$ Department of Oncology, Unit of Thoraic Surgery, University of Torino, Italy

${ }^{k}$ Department of Surgical Oncology, National Cancer Center Hospital East, Kashiwa, Chiba, Japan

'Service de Chirurgie Thoracique, Centre Hospitalier Universitaire Vaudois, Lausanne, Switzerland

mDepartment of Surgery, University Hospital Geneva, Geneva, Switzerland

${ }^{n}$ Clinical Epidemiology Unit, Hospital Universitario Donostia, UPV/EHU, CIBER-ESP, CASPe, Biodonostia, Donostia, Spain

Unidad de Bioestadística Clínica, Hospital Universitario Ramón y Cajal, IRYCIS, CIBER-ESP, Madrid, Spain

*Corresponding author E-mail addresses: jon.zabaletajimenez@osakidetza.eus (J. Zabaleta), skcho@snubh.org (S. Cho) 


\begin{abstract}
Objectives

To assess the impact of a history of liver metastases on survival in patients undergoing surgery for lung metastases from colorectal carcinoma.

\section{Methods}

We reviewed recent studies identified by searching MEDLINE and EMBASE using the Ovid interface, with the following search terms: lung metastasectomy, pulmonary metastasectomy, lung metastases and lung metastasis, supplemented by manual searching. Inclusion criteria were that the research concerned patients with lung metastases from colorectal cancer undergoing surgery with curative intent, and had been published between 2007 and 2014. Exclusion criteria were that the paper was a review, concerned surgical techniques themselves (without follow-up), and included patients treated non-surgically. Using Stata 14, we performed aggregate data and individual data metaanalysis using random-effect and Cox multilevel models respectively.
\end{abstract}

\title{
Results
}

We collected data on 3501 patients from 17 studies. The overall median survival was 43 months. In aggregate data meta-analysis, the hazard ratio for patients with previous liver metastases was 1.19 (95\% CI 0.90-1.47), with low heterogeneity (I2 4.3\%). In individual data meta-analysis, the hazard ratio for these patients was 1.37 (95\% CI 1.14-1.64; $\mathrm{p}<0.001)$. Multivariate analysis identified the following factors significantly affecting survival: tumour-infiltrated pulmonary lymph nodes ( $\mathrm{p}<$ 0.001), type of resection $(p=0.005)$, margins $(p<0.001)$, carcinoembryonic antigen levels $(p<$ 0.001 ), and number and size of lung metastases (both $\mathrm{p}<0.001$ ).

\section{Conclusions}

A history of liver metastases is a negative prognostic factor for survival in patients with lung metastases from colorectal cancer. We registered the meta-analysis protocol in PROSPERO (CRD42015017838).

\section{Introduction}

Pulmonary metastasectomy has become the standard treatment for patients with lung metastases from colorectal cancer (CRC) [1]. In Western countries, colon canceris the most prevalent type of cancer considering both sexes [2], and $50 \%$ of patients with this type of cancer will develop metastases during the course of the disease, primarily in the liver, lung or both [2].

Although a large number of studies have been published with data on survival after surgical resection of lung metastases [3], there are certain outstanding issues, including a lack of agreement on the best prognostic factors. In 1997, to address this issue, the International Registry of Lung Metastases reported the prognostic factors associated with this type of surgery, after analysing survival rates in a sample of more than 5000 patients [4]. A decade later, in 2007, Pfannschmidt and colleagues conducted a systematic review to identify specific prognostic factors in patients with lung metastases from CRC [3]. Since then, many different factors have been found to be associated with prolonged survival after lung metastasectomy in patients with CRC [5], [6], [7]: prolonged disease-free interval, low pre-thoracotomy carcinoembryonic antigen (CEA) levels, a single lung metastasis less than $3 \mathrm{~cm}$ in diameter and the absence of thoracic lymph node involvement. However, the real impact of a 
history of resected liver metastases on survival outcomes following lung metastasectomy remains uncertain [5].

In 2013, Gonzalez et al. [8] published a systematic review and meta-analysis of papers published between 2000 and 2011. They analysed seven studies that took into account previous liver metastasis and concluded that a history of resected liver metastasis is not correlated with a higher risk of mortality in these patients (hazard ratio, HR 1.22, 95\% CI: 0.91-1.64; $\mathrm{p}=0.022$ ); however, the observed high heterogeneity of the data analysed might have influenced the interpretation and the conclusions in that analysis. Given the uncertainties about the impact of a history of resected liver metastasis on survival outcomes of CRC following lung metastasectomy, we sought to conduct a systematic review of recent scientific literature, considering papers published since Pfannschmidt's 2007 systematic review [3], and asking authors for their collaboration to enable us to perform an individual data meta-analysis. The aim of this study was to provide the best evidence on a question of great current interest, namely, the impact of a history of liver metastases on survival of patients undergoing surgery for lung metastases from CRC.

\section{Materials and methods}

\section{Search strategy}

Studies were identified by searching MEDLINE and EMBASE using the Ovid interface, supplemented by a manual search of the reference lists of the papers retrieved. The following terms were used: lung metastasectomy, pulmonary metastasectomy, lung metastases and lung metastasis. All the search terms were combined using the Boolean operator "OR" to increase the likelihood of retrieving all relevant articles, and the search was limited to publications between 2007 and 2014.

Fig. 1 is a diagram showing the flow of papers through the study. We sought to identify papers that analysed variables with an impact on survival after lung metastasectomy in patients with colorectal cancer. To identify papers that met all the inclusion criteria and none of the exclusion criteria, two reviewers independently assessed the relevance of the papers identified, by reading the titles, then the abstracts and, finally, by reading the full paper and confirming that they had some data relevant to our research question; disagreements were resolved by discussion and consensus. The inclusion criteria were that the research was in consecutive patients with lung metastases from colorectal cancer undergoing surgery with curative intent, and had been published between 2007 and 2014, considering both retrospective and prospective studies. When a study led to more than one paper, we used data from the most recent publication. The exclusion criteria considered were that the paper was a review, concerned the surgical techniques themselves, did not report follow-up of patients undergoing surgery, or included patients treated with non-surgical approaches (stereotactic radiotherapy or radiofrequency ablation). This process resulted in the selection of a total of 29 papers. 
PRISMA 2009 Flow Diagram
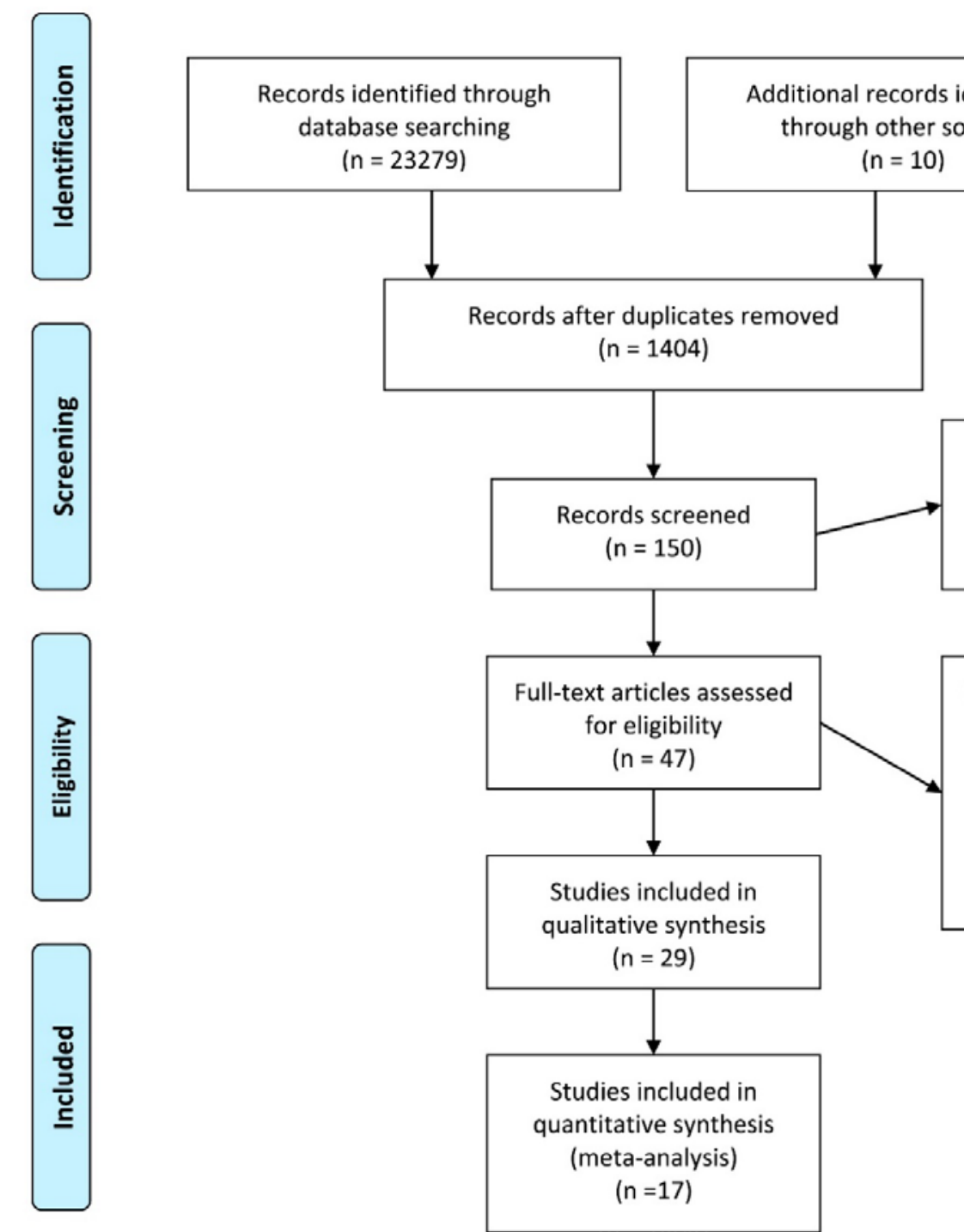

Records excluded because paper was a review, concerned the surgical techniques themselves $(n=103)$

Full-text articles excluded because did not report follow-up of patients undergoing surgery, or included patients treated with non-surgical approache with reasons $(n=18)$

Fig. 1. Flow chart of the search and selection process.

\section{Data collection}

We registered the protocol for the meta-analysis with PROSPERO (registration number CRD42015017838; supplementary file 1) and drafted a collaboration agreement to share specific data (Supplementary file 2). Additionally, we designed a database to store all the data we wanted to analyse from the studies of interest and the study was approved by the clinical research ethics committee of the Gipuzkoa health region. To contact study authors, we initially sent an email explaining our interest to the corresponding author cited on the paper retrieved. If we did not receive a reply, we sent emails directly to the other authors and we also attempted to contact some authors via social media, including Facebook, Twitter and ResearchGate. 


\section{Statistical analysis}

We performed two types of meta-analysis. First, we carried out conventional meta-analysis of aggregate data with both crude and adjusted estimates using a random-effect model. Second, we carried out one-step meta-analysis of individual participant data using a multilevel Cox model with the patients as level 1 units and the studies as level 2 units. We fitted both a univariate model with the main variable (previous liver metastasectomy) and a multivariate model. The variables in these models (as for the meta-analysis of aggregate data) were selected a priori with clinical criteria, seeking to control for confounding factors, with no modelling strategy. To be able to include random effects on the intercept and slope of the model (to allow for heterogeneity between studies in baseline risk and effect respectively), the Cox model was simulated using a Poisson model [9]. As a measure of heterogeneity, we used the median hazard ratio (MHR), that can be interpreted as the median relative change in the hazard of the occurrence of the outcome when comparing identical subjects from two randomly selected studies ordered by risk [10]. The assumption of proportional risk for the main variable given the other variables was tested by introducing a term for interaction with time.

\section{Results}

\section{Studies included}

We selected 29 papers that met all the selection criteria and divided them into two broad groups: 6 which did not analyse the variable of interest [2], [6], [7], [11], [12], [13], that is, whether patients who underwent surgery had a history of resected liver metastases; and the other 23 which did consider this variable [1], [5], [14], [15], [16], [17], [18], [19], [20], [21], [22], [23], [24], [25], [26], [27], [28], [29], [30], [31], [32], [33]. In this second group of 23 papers, there were 21 patient series, 1 prospective [15] and the others retrospective [5], [14], [16], [17], [18], [19], [20], [21], [22], [23], [24], [25], [26], [27], [28], [29], [30], [31], [32], and 2 meta-analyses [1], [8] (these including several of the selected patient series). In total, we collected data from 17 studies [2], [5], [12], [13], [14], [16], [17], [18], [20], [21], [25], [26], [27], [28], [30], [32], [33], managing to obtain data on 3501 patients for the meta-analysis of individual data. The authors from three studies [6], [15], [31] replied to the first email, expressing interest in the study, but did not communicate further, and did not provide any information or explain their reasons; one author replied declining to participate in the study [19]; and authors of the other studies [7], [11], [22], [23], [24], [29] did not respond to any of our attempts to contact them.

\section{Descriptive analysis}

The mean age of patients who underwent surgery was 62.7 years (range: 19-94), 2126 (60.7\%) were male, and 744 (20\%) had a history of liver metastases. Table 1summarises the main descriptive variables of the study, as well as their distribution as a function of whether patients had previously had liver metastasis. 
Table 1. Main descriptive variables of the study (univariate analysis).

\begin{tabular}{|c|c|c|c|c|c|}
\hline Study variable & $\begin{array}{l}\text { Number of } \\
\text { patients with this } \\
\text { type of data }\end{array}$ & All cases & $\begin{array}{l}\text { No previous liver } \\
\text { metastasis }\end{array}$ & $\begin{array}{l}\text { Previous liver } \\
\text { metastasis }\end{array}$ & $\mathbf{p}$ \\
\hline Age in years, mean (SD) & 3500 & $62.7(10.33)$ & $63.17(10.12)$ & $60.81(10.89)$ & 0.061 \\
\hline Sex: male, n (\%) & 3501 & $2126(60.7)$ & $1662(60.3)$ & $464(62.4)$ & 0.302 \\
\hline $\begin{array}{l}\text { Disease-free interval in } \\
\text { months, mean (SD) }\end{array}$ & 3331 & $34.01(35.12)$ & $34.33(36.8)$ & $32.83(28.27)$ & 0.351 \\
\hline $\begin{array}{l}\text { Number of lung metastasis, } \\
\text { mean (SD) }\end{array}$ & 2821 & $1.97(2.09)$ & $1.87(1.93)$ & $2.33(2.56)$ & $<0.001$ \\
\hline $\begin{array}{l}\text { Size of metastases, mean } \\
\text { (SD) }\end{array}$ & 2876 & $2.35(1.54)$ & $2.44(1.50)$ & $2.06(1.36)$ & 0.002 \\
\hline $\begin{array}{l}\text { Lymph node involvement: } \\
\text { positive, } \mathrm{n}(\%)\end{array}$ & 2095 & $401(19.1)$ & $328(19.5)$ & $73(17.5)$ & 0.343 \\
\hline $\begin{array}{l}\text { Surgery: video-assisted } \\
\text { thoracic, } \mathrm{n}(\%)\end{array}$ & 2459 & $608(17.4)$ & $485(24.4)$ & $123(26.2)$ & 0.440 \\
\hline $\begin{array}{l}\text { Preoperative CEA: positive, } \\
\text { n (\%) }\end{array}$ & 3025 & 1035 (34.2) & $831(34.8)$ & $204(32.0)$ & 0.190 \\
\hline Margins: positive, n (\%) & 2953 & $156(5.3)$ & $92(4)$ & $64(10)$ & $<0.001$ \\
\hline Origin: rectal, n (\%) & 2534 & $1212(47.8)$ & $1015(50.2)$ & $197(38.5)$ & $<0.001$ \\
\hline
\end{tabular}

CEA: carcinoembryonic antigen; SD: standard deviation.

\section{Survival analysis}

The overall median survival from lung metastasectomy was 64 months (range: 0-275 months), while the 3 - and 5-year survival rates were $68.6 \%$ and $51.9 \%$ respectively. In the univariate analysis, we did not find significant differences by sex $(\mathrm{p}=0.261)$ or site of the primary tumour (colon or rectum) $(p=0.254)$. The type of surgery performed was close to significance $(p=0.055)$. We did find statistically significant differences for the following variables: lymph node involvement ( $p<0.001)$, CEAlevel $(p<0.001)$, state of the surgical margins $(p<0.001)$, history of liver metastases $(p<0.001)$, disease-free interval $(p=0.029)$, number of metastases $(p<0.001)$ and their size ( $\mathrm{p}<0.001)$. Fig. 2 shows the Kaplan-Meier survival curves as a function of whether patients had previously had liver metastases. 


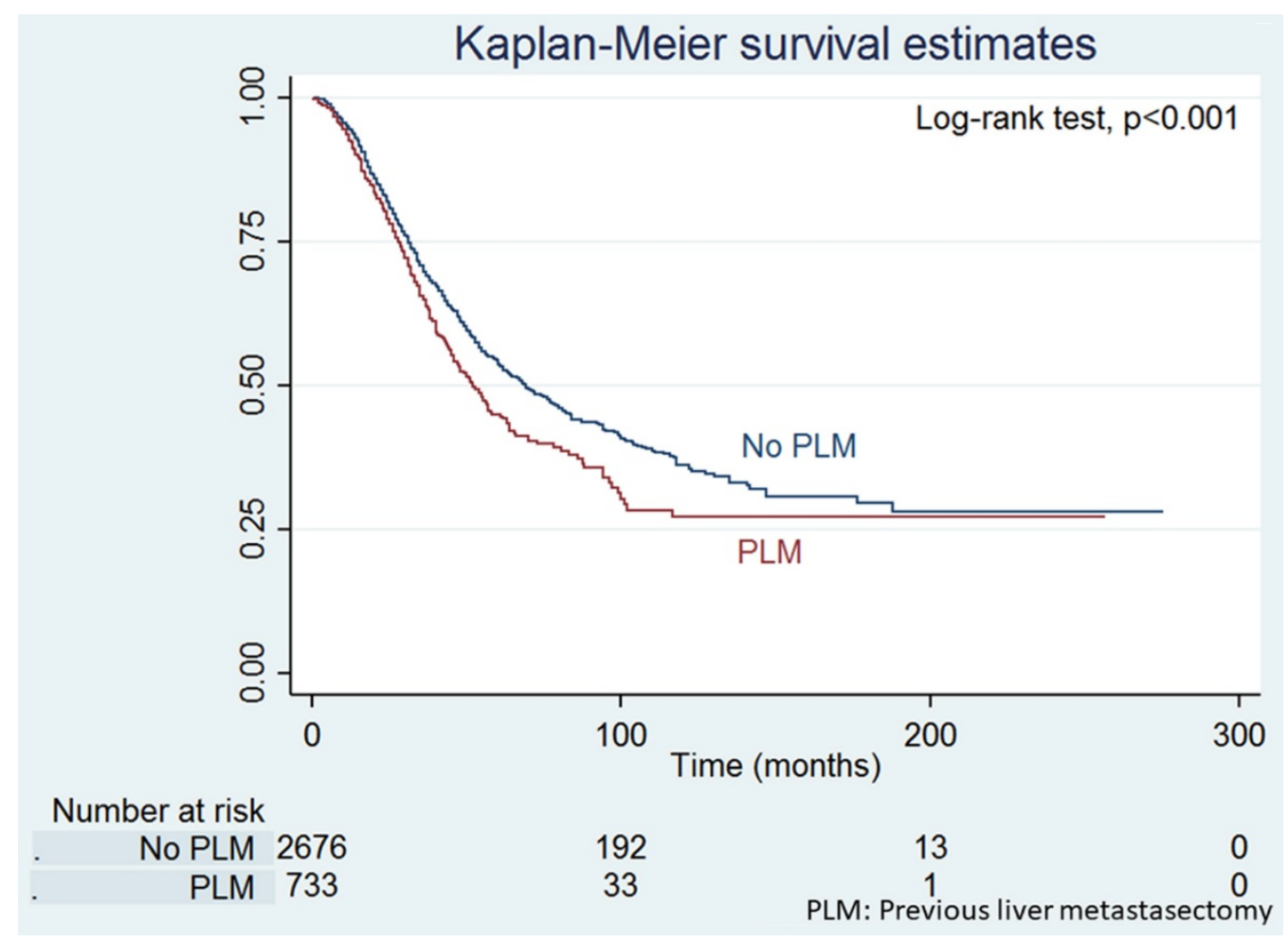

Fig. 2. Kaplan-Meier survival curves for the 3501 patients included in the study.

\section{Previous liver metastasis}

For the group of 744 patients with a history of liver metastases, we estimated a median survival of 51.8 months (95\% CI: 46.11-57.49), with mean 3- and 5-year survival rates of $64 \%$ and $44.5 \%$, respectively. In patients for whom there were data on the time elapsed between the appearance of liver and lung metastasis, we found that 135 (49.5\%) patients had metachronous metastases and 138 (50.5\%) synchronous metastases. We did not find significant differences in survival between these groups, with mean survival of 55 (95\% CI 41.5-68.4) and 46 (95\% CI: 37.61-54.39) months among those with synchronous and metachronous metastases, respectively $(\mathrm{p}=0.215)$.

\section{Aggregate data and individual participant data meta-analysis}

Two types of aggregate data meta-analysis were performed with raw and adjusted data (Fig. 3, Fig. 4). Fig. 3 shows the aggregate data meta-analysis, with all the participating studies. We excluded the studies of Landes [21] and Nojiri [33] from the analysis, because they only included patients with a history of liver metastases, and hence could not be used to study the impact of previous liver metastasis on survival. 


\section{HR random effects crude meta-analysis}

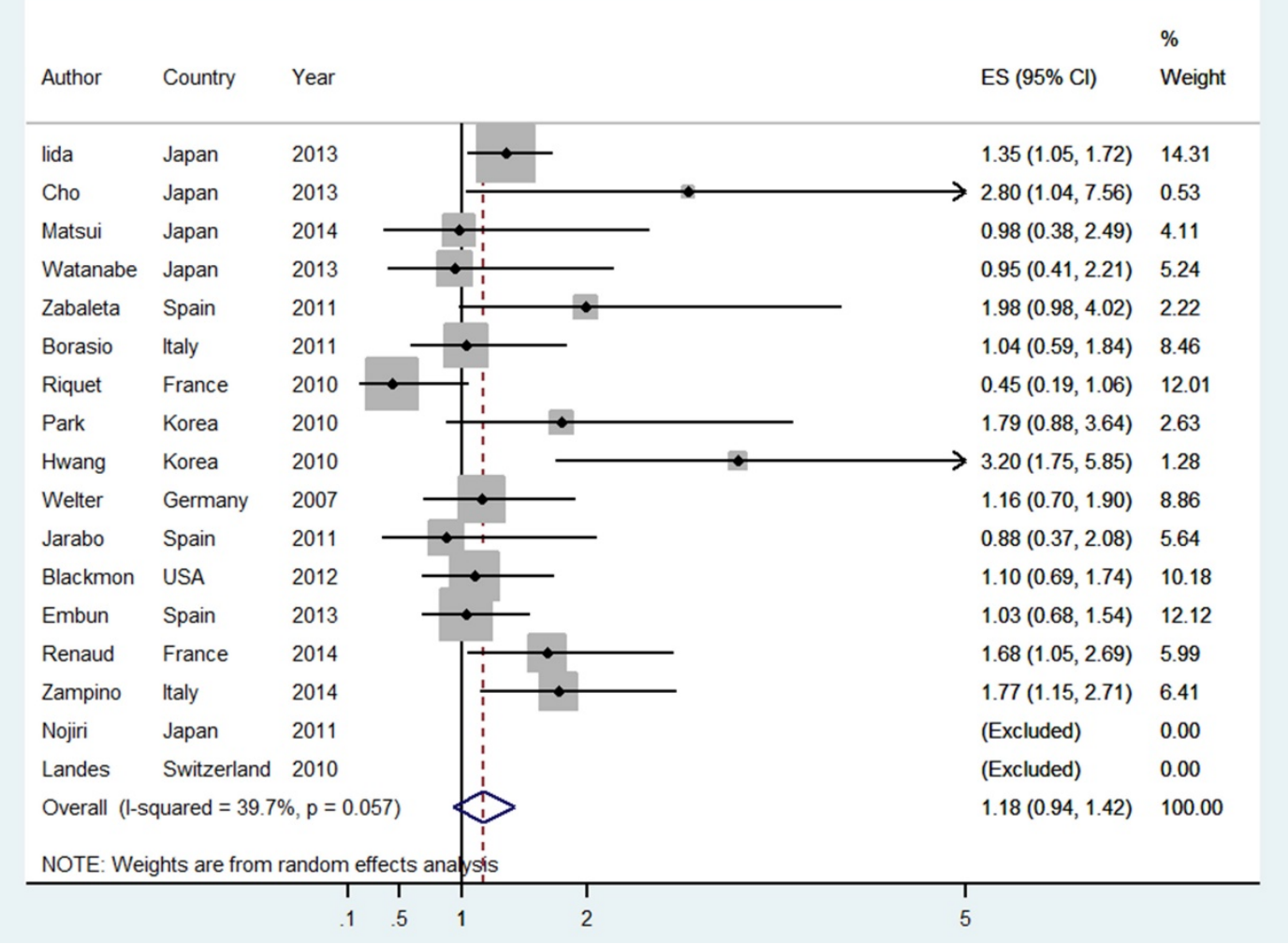

Fig. 3. Forest plot for the aggregate data meta-analysis of the raw data.

\section{HR random effects adjusted meta-analysis}

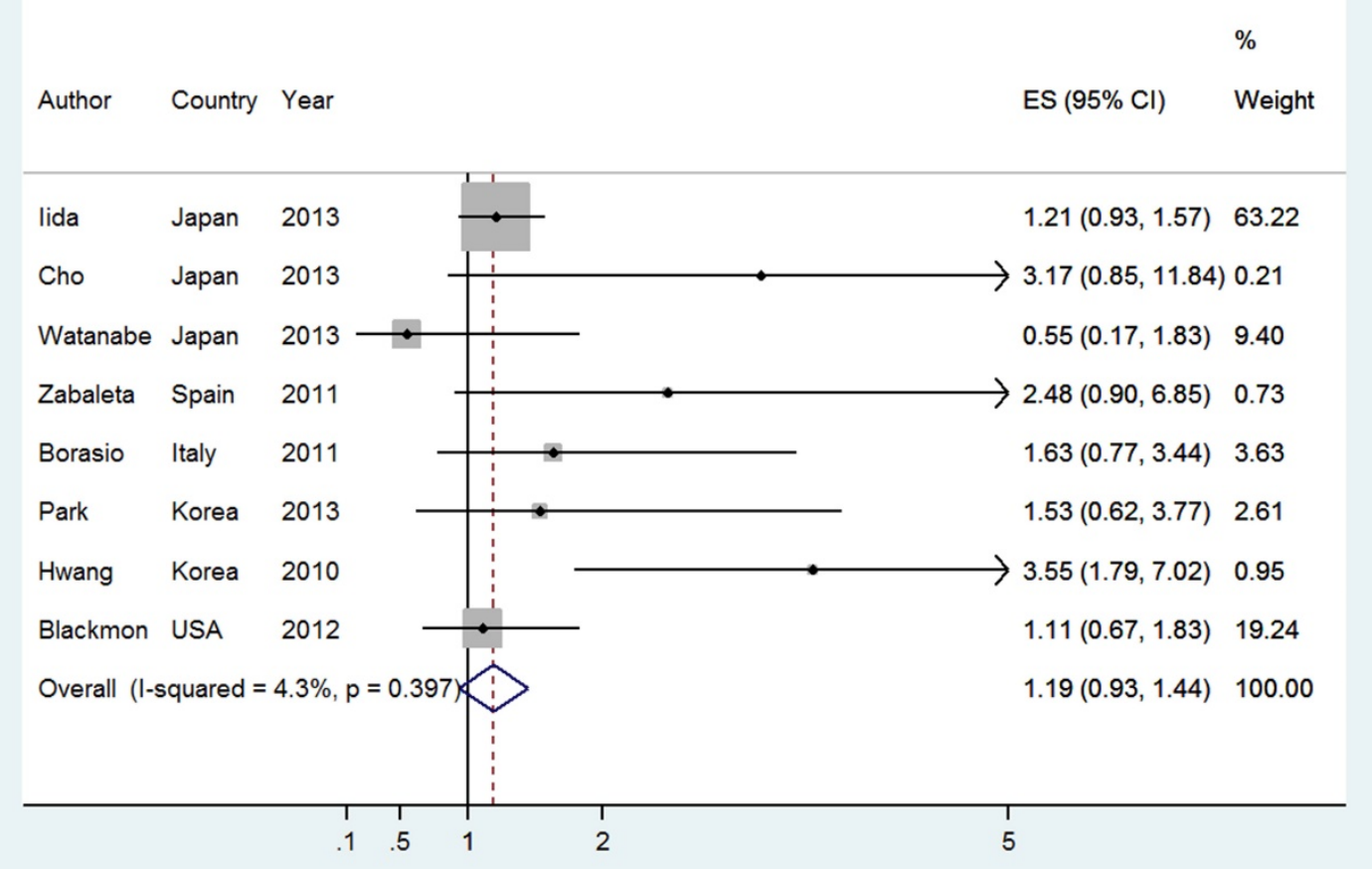

Fig. 4. Forest plot for the adjusted aggregate data meta-analysis. 
In both the adjusted aggregate data meta-analysis and the individual participant data meta-analysis, to assess the impact of previous liver metastasis, we adjusted for variables which from a clinical point of view are associated with prognosis, namely, sex, age, mediastinal lymph node involvement, type of resection, surgical margin status, number of metastases and their size, preoperative CEA levels, and disease-free interval (for this analysis we included 1779 patients, where all this variables were recorded).

The combined estimator (for previous liver metastasis) obtained from aggregate data using a randomeffect model did not reach statistical significance (HR $=1.19$, 95\% CI 0.90-1.47), with a low level of heterogeneity $\left(\mathrm{I}^{2} 4.3 \%\right.$ ) (see also Fig. 4, a Forest plot for the adjusted aggregate data meta-analysis with the studies that included all the variables to perform the adjustment). In contrast, the estimator obtained from the individual participant data meta-analysis, using an adjusted multilevel random effects Cox model (Table 2), was statistically significant (HR = 1.37, 95\% CI 1.14-1.64). Though no heterogeneity was detected in effects, there was heterogeneity in baseline risks (MHR $=1.17,95 \%$ CI 1.07-1.47).

Table 2. Individual data meta-analysis (multilevel random effects).

\begin{tabular}{lccccc}
\hline Variable & Hazard ratio & $\mathbf{9 5 \%} \mathbf{C I}$ & Std error & $\mathbf{Z}$ & $\mathbf{p}$ \\
\hline Previous liver metastasis & 1.37 & $1.14-1.64$ & 0.13 & 3.44 & 0.001 \\
Sex & 0.92 & $0.79-1.08$ & 0.07 & -0.99 & 0.323 \\
Age & 1.00 & $0.99-1.01$ & 0.01 & 0.99 & 0.324 \\
Positive lymph nodes & 1.83 & $1.44-2.32$ & 0.22 & 4.96 & $<0.001$ \\
Positive margins & 1.81 & $1.35-2.42$ & 0.27 & 3.95 & $<0.001$ \\
Size of metastases & 1.12 & $1.06-1.18$ & 0.03 & 4.10 & $<0.001$ \\
Preoperative CEA level & 1.51 & $1.28-1.77$ & 0.13 & 4.86 & $<0.001$ \\
Disease-free interval & 0.99 & $0.99-0.99$ & 0.001 & -2.05 & 0.040 \\
Number of metastases & 1.07 & $1.04-1.09$ & 0.10 & 6.86 & $<0.001$ \\
Lobectomy (vs wedge) & 0.78 & $0.63-0.96$ & 0.08 & -2.31 & 0.021 \\
Pneumonectomy (vs wedge) & 2.34 & $0.56-9.73$ & 1.70 & 1.17 & 0.243 \\
\hline
\end{tabular}

CEA: carcinoembryonic antigen. 


\section{Discussion}

What factors are prognostic of lung metastases is a topic of ongoing debate, and this is reflected in the numerous studies analysing potentially relevant factors [1], [3], [4], [8]. In 1997, the International Registry of Lung Metastases published its results, finding only disease-free survival, the radicality of the surgery, and the number of lymph nodes removed to be determinant [4], but since then, several studies have indicated a wider range of prognostic factors, such as mediastinal lymph nodeinvolvement, preoperative CEA levels or age [5], [6], [7].

To date, however, no results have been published from clinical trials on lung metastasectomy. We await the results of the PulMICC trial for good quality scientific evidence to clarify uncertainties related to this type of surgery [34], but meanwhile, systematic reviews of case series are the best source of scientific evidence. In 2007, Pfannschmidt et al. researched lung metastases from colorectal cancer in detail, conducting a systematic review and a meta-analysis to assess prognostic factors, and found that up to that point, little attention had been paid to whether patients had a history of liver metastases [3]. Later Gonzalez [8] carried out a new systematic review and meta-analysis including four studies that had been published after 2007. Three out of these four studies found that a history of resected liver metastases was associated with shorter survival [5], [21], [22].

In our new systematic review, we have found 21 papers published since 2007 that assessed survival after resection of lung metastases from colorectal cancer taking into account patients' history of liver metastases. Like Gonzalez [8], we found a great heterogeneity in the studies, with some authors reporting their results as mean survival time [5], [16], [17], [18] (with or without confidence intervals), 5-year survival rates [20], [27], or HRs [30], while others simply stated that differences were not statistically significant, without reporting the actual results [28], [30]. Gonzalez et al. [8] reviewed papers published between 2000 and 2011. They analysed seven studies that took into account previous liver metastasis and concluded that a history of resected liver metastases is not correlated with a higher risk of mortality in these patients (HR 1.22, 95\% CI: 0.91-1.64), but also highlighted the high heterogeneity of the data analysed $(p=0.022)$. Seeking to improve on that analysis, we decided to conduct a meta-analysis of individual data, to assess the impact of a history of liver metastases on survival, and we have found that patients who have previously undergone liver metastasectomy have poorer survival (HR 1.37, 95\% CI: 1.14-1.64).

To our knowledge, this is the first time that an individual data meta-analysis has been performed to analyse survival after lung metastases, and for this, we have assembled the series with the largest number of patients with metastasis with a colorectal origin published to date. In the meta-analysis published by Gonzalez [8], four negative prognostic factors were identified: short disease-free interval (HR 1.59; 95\% CI 1.27-1.98), the presence of lymph node involvement (HR 1.65; 95\% CI 1.35-2.02), having more than one lung metastasis (HR 2.04; 95\% CI 1.72-2.41) and high CEA levels (HR 1.91; 95\% CI 1.57-2.32). The results obtained from analysing the large sample of patients we have assembled enable us to add the following to this list of negative prognostic factors: positive surgical margins (HR 1.81; 95\% CI 1.35-2.43), larger metastases (HR 1.12; 95\% CI 1.06-1.18) and a history of liver metastases (HR 1.37; 95\% CI 1.15-1.64). The statistical analysis performed, simulating the Cox model with a Poisson model, has allowed us to study the heterogeneity not only in baseline risk but also in effects. Specifically, this modelling was necessary to enable us to rule out heterogeneity in the effects and it allows us to conclude that, despite the baseline risk of patients varying between studies included, the effect on survival of the factors analysed, in particular, that of a history of previous liver metastases, is similar across the studies.

One fact that has caught our attention is the amount of missing data: in 1406 cases there was no data on lymph node involvement, in 1001 cases it was not known if the primary tumour was rectal or colon, in 1042 cases we did not know the surgical approach chosen and there was a lack of data on the size or number of metastases in 600 patients. We believe that the absence of data supports the 
need to make the extra effort involved in obtaining individual data to perform individual data metaanalysis of individual data, as this will achieve the most reliable results.

We should also point out that we found shorter survival in patients who underwent surgery with wedge resection rather than lobectomy (HR 0.78, 95\% CI: 0.63-0.96). Hernández et al. [35] made a similar observation based on analysing the results of a Spanish prospective multicentre study, and a few years earlier, Lin et al. [22] also observed a shorter survival in patients who underwent less complete resection. These results do not allow us to recommend lobectomies in patients undergoing pulmonary metastasectomy, but do suggest a new avenue for research. Specifically, it would be interesting to carry out a prospective randomised study comparing the two techniques, deciding a priori which type of lymphadenectomy is to be performed [35].

\section{Conclusions}

Given the results of our meta-analysis of individual participant data, it can be concluded that a history of liver metastases prior to resection of lung metastasesfrom colorectal carcinoma is associated with a poorer prognosis. In addition, other factors have been found to have an impact on survival after lung metastasectomy, namely, disease-free interval, lymph node involvement, infiltrated surgical margins, preoperative CEA levels, the number of resected lung metastases and their size.

\section{Funding}

No external funding was received for this study.

\section{Conflicts of interest statement}

The authors declare no conflicts of interest. 


\section{References}

[1] S. Salah, K. Watanabe, S. Welter, J.S. Park, J.W. Park, J. Zabaleta, et al.Colorectal cancer pulmonary oligometastases: pooled analysis and construction of a clinical lung metastasectomy prognostic model Ann Oncol, 10 (2012), pp. 2649-2655

[2] M.G. Zampino, P. Maisonneuve, P.S. Ravenda, E. Magni, M. Casiraghi, P. Solli, et al.Lung metastases from colorectal cancer: analysis of prognostic factors in a single institution study Ann Thorac Surg, 98 (2014), pp. 1238-1245

[3] J. Pfannschmidt, H. Dienemann, H. HoffmannSurgical resection of pulmonary metastases from colorectal cancer: a systematic review of published series Ann Thorac Surg, 84 (2007), pp. 324-328

[4] U. Pastorino, M. Buyse, G. Friedel, R.J. Ginsberg, P. Girard, P. Goldstraw, et al.Long-term results of lung metastasectomy: prognostic analyses based on 5206 cases J Thorac Cardiovasc Surg, 113 (1997), pp. 37-49

[5] J. Zabaleta, B. Aguinagalde, M.G. Fuentes, N. Bazterargui, J.M. Izquierdo, C.J.Hernandez, et al.Survival after lung metastasectomy for colorectal cancer: importance of previous liver metastasis as a prognostic factor Eur J Surg Oncol, 37 (2011), pp. 786-790

[6] R.N. Younes, F. Abrao, J. GrossPulmonary metastasectomy for colorectal cancer: longterm survival and prognostic factors Int J Surg, 11 (2013), pp. 244-248

[7] N. Rama, A. Monteiro, J.E. Bernardo, L. Eugénio, M.J. AntunesLung metastases from colorectal cancer: surgical resection and prognostic factors Eur J Cardio Thorac Surg, 35 (2009), pp. 444-449

[8] M. Gonzalez, A. Poncet, C. Combescure, J. Robert, H.B. Ris, P. GervazRisk factors for survival after lung metastasectomy in colorectal cancer patients: a systematic review and meta-analysis Ann Surg Oncol, 20 (2013), pp. 572-579

[9] S. Rabe-Hesketh, A. SkrondalMultilevel and longitudinal modeling using stata Stata Press, College Station, TX (2012)

[10] P.C. Austin, P. Wagner, J. MerloThe median hazard ratio: a useful measure of variance and general contextual effects in multilevel survival analysis Stat Med, 36 (2017), pp. 928938

[11] M. Krüger, J.D. Schmitto, B. Wiegmann, T.K. Rajab, A. HaverichOptimal timing of pulmonary metastasectomy-is a delayed operation beneficial or counterproductive? Eur $\mathrm{J}$ Surg Oncol, 40 (2014), pp. 1049-1055

[12] R. Embun, F. Fiorentino, T. Treasure, J.J. Rivas, L. MolinsOn behalf of Grupo Español de Cirugía Metástasis Pulmonares de Carcinoma Colo-Rectal (GECMP-CCR) de la Sociedad Española de Neumoloña y Cirurgía Torácica (SEPAR). Pulmonary metastasectomy in colorectal cancer: a prospective study of demography and clinical characteristics of 543 patients in the Spanish colorectal metastasectomy registry (GECMP-CCR) BMJ Open, 3 (2013) e002787

[13] S.H. Blackmon, E.H. Stephens, A.M. Correa, W. Hofstetter, M.P. Kim, R.J. Mehran, et al.Predictors of recurrent pulmonary metastases and survival after pulmonary metastasectomy for colorectal cancer Ann Thorac Surg, 94 (2012), pp. 1802-1809 
[14] J.S. Park, H.K. Kim, Y.S. Choi, K. Kim, Y.M. Shim, J. Jo, et al.Outcomes after repeated resection of recurrent pulmonary metastases from colorectal cancer Ann Oncol, 21 (2010), pp. 1285-1289

[15] M.A. Javed, A.R. Sheel, A.A. Sheikh, R.D. Page, P.S. RooneySize of metastatic deposits affects prognosis in patients undergoing pulmonary metastasectomy for colorectal cancer Ann R Coll Surg Engl, 96 (2014), pp. 32-36

[16] S. Renaud, M. Alifano, P.E. Falcoz, P. Magdeleinat, N. Santelmo, O. Pagès, et al.Does nodal status influence survival? Results of a 19-year systematic lymphadenectomy experience during lung metastasectomy of colorectal cancer Interact Cardiovasc Thorac Surg, 18 (2014), pp. 482-487

[17] S. Cho, I.H. Song, H.C. Yang, S. JheonPrognostic factors of pulmonary metastasis from colorectal carcinoma Interact Cardiovasc Thorac Surg, 17 (2013), pp. 303-307

[18] T. Iida, H. Nomori, M. Shiba, J. Nakajima, S. Okumura, H. Horio, et al.Prognostic factors after pulmonary metastasectomy for colorectal cancer and rationale for determining surgical indications: a retrospective analysis Ann Surg, 257 (2013), pp. 1059-1064

[19] N. Hattori, Y. Kanemitsu, K. Komori, Y. Shimizu, T. Sano, Y. Senda, et al.Outcomes after hepatic and pulmonary metastasectomies compared with pulmonary metastasectomy alone in patients with colorectal cancer metastasis to liver and lungs World $\mathrm{J}$ Surg, 37 (2013), pp. 1315-1321

[20] M.R. Hwang, J.W. Park, D.Y. Kim, H.J. Chang, S.Y. Kim, H.S. Choi, et al.Early intrapulmonary recurrence after pulmonary metastasectomy related to colorectal cancer Ann Thorac Surg, 90 (2010), pp. 398-404

[21] U. Landes, J. Robert, T. Perneger, G. Mentha, V. Ott, P. Morel, et al.Predicting survival after pulmonary metastasectomy for colorectal cancer: previous liver metastases matter BMC Surg, 10 (2010), pp. 17-22

[22] B.R. Lin, T.C. Chang, Y.C. Lee, P.H. Lee, K.J. Chang, J.T. LiangPulmonary resection for colorectal cancer metastases: duration between cancer onset and lung metastasis as an important prognostic factor Ann Surg Oncol, 16 (2009), pp. 1026-1032

[23] R. Suemitsu, S. Takeo, E. Kusumoto, M. Hamatake, K. Ikejiri, H. SaitsuResults of a pulmonary metastasectomy in patients with colorectal cancer Surg Today, 41 (2011), pp. 54-59

[24] M. Kamiyoshihara, H. Igai, N. Kawatani, T. Ibe, N. Tomizawa, K. Obayashi, et al.Lung metastasectomy for postoperative colorectal cancer in patients with a history of hepatic metastasis Gen Thorac Cardiovasc Surg, 62 (2014), pp. 314-320

[25] T. Matsui, T. Kitamura, H. Ozawa, H. Matsuguma, K. KotakeAnalysis of treatment that includes both hepatic and pulmonary resections for colorectal metastases Surg Today, 44 (2014), pp. 702-711

[26] J.R. Jarabo, E. Fernández, J. Calatayud, A.M. Gómez, C. Fernández, A.J. Torres, et al.More than one pulmonary resections or combined lung-liver resection in 79 patients with metastatic colorectal carcinoma J Surg Oncol, 104 (2011), pp. 781-786 
[27] M. Riquet, C. Foucault, A. Cazes, E. Mitry, A. Dujon, F. Le Pimpec Barthes, et al.Pulmonary resection for metastases of colorectal adenocarcinoma Ann Thorac Surg, 89 (2010), pp. $375-380$

[28] K. Watanabe, K. Nagai, A. Kobayashi, M. Sugito, N. SaitoFactors influencing survival after complete resection of pulmonary metastases from colorectal cancer Br J Surg, 96 (2009), pp. 1058-1065

[29] F. Chen, T. Shoji, H. Sakai, R. Miyahara, T. Bando, K. Okubo, et al.Lung metastasectomy for colorectal carcinoma in patients with a history of hepatic metastasis Ann Thorac Cardiovasc Surg, 17 (2011), pp. 13-18

[30] P. Borasio, M. Gisabella, A. Billé, L. Righi, M. Longo, M. Tampellini, et al.Role of surgical resection in colorectal lung metastases: analysis of 137 patients Int J Colorectal Dis, 26 (2011), pp. 183-19

[31] N.K. Perera, S.R. KnightOutcomes after pulmonary metastasectomy for colorectal cancer ANZ J Surg, 84 (2014), pp. 556-559

[32] S. Welter, J. Jacobs, T. Krbek, C. Poettgen, G. StamatisPrognostic impact of lymph node involvement in pulmonary metastases from colorectal cancer Eur J Cardio Thorac Surg, 31 (2007), pp. 167-172

[33] K. Nojiri, K. Tanaka, Y. Nagano, M. Ueda, K. Matsuo, M. Ota, et al.Efficacy of surgery for lung metastases from colorectal cancer synchronous to or following that for liver metastases Anticancer Res, 31 (2011), pp. 1049-1054

[34] T. Treasure, L. Fallowfield, B. LeesPulmonary metastasectomy in colorectal cancer: the PulMiCC trial Thorax, 67 (2012), pp. 185-187

[35] J. Hernández, L. Molins, J.J. Fibla, F. Heras, R. Embún, J.J. RivasGrupo Español de Metástasis Pulmonares de Carcinoma Colo-Rectal (GECMP-CCR) de la Sociedad Española de Neumología y Cirugía Torácica (SEPAR). Role of major resection in pulmonary metastasectomy for colorectal cancer in the Spanish prospective multicenter study (GECMP-CCR) Ann Oncol, 27 (2016), pp. 850-855 